\title{
The Liberian mongoose
}

\author{
Mark E. Taylor
}

The Liberian mongoose Liberiictis kuhni, the only member of its genus, was described as a new species from skulls in 1958. The first two complete specimens were obtained as recently as 1974. Although several more animals have been captured since then, all in Liberia, the species's status and ecology remain poorly known. In 1988 the FFPS contributed $£ 500$ towards a field study of the mongoose in Liberia and while this expedition succeeded in finding only one animal that had been killed by a hunter, a subsequent attempt in 1989 was more successful. In 1990 the Liberian mongoose was also recorded for the first time in the Côte d'Ivoire.

In 1957 a new genus of mongoose, the Liberian mongoose Liberiictis kuhni was discovered (Hayman, 1958). It was described on the basis of eight skulls, which were collected from villagers in north-eastern Liberia and sent to Professor Kuhn in Germany, who, not knowing what these animals were, sent them to Dr Hayman at the British Museum (Natural History). Hayman realized that the skulls were different from any other mongooses, and described the new species. It was not until 1974 that the first two complete specimens were collected by an American team and the animal's external appearance described (Schlitter, 1974).

Liberian mongooses weigh about $2 \mathrm{~kg}$ and are a rich brown colour with light and dark stripes on the sides of the neck. They have a distinctive long pointed nose and their front claws are very long. The mouth seems rather small and is tucked underneath its nose; its cheek teeth are very reduced in size, although the canines are long and quite formidable in appearance (Hayman, 1958; Schlitter, 1974; Taylor, 1989; Goldman and Taylor, 1990, H. Kuhn, in litt.). Although several more animals were caught in the next 15 years (Figure 1), very little was learnt about their ecological requirements. The specimens collected had all come from locations in eastern Liberia, and had been caught by native hunters using guns, snares or dogs. According to the villagers, they were collected in low-lying areas, near watercourses on the edges of forests. Kuhn suggested that they are specialized invertebrate-feeders because of the reduced cheek teeth and the remains of worms in several stomachs.

In 1988 I spent 6 weeks trapping for Liberian mongooses without success in Sapo National Park, which had recently been gazetted and was relatively free from hunting (Frame and Schmude, 1986). I also travelled to many villages in eastern Liberia and obtained a partially cooked specimen of Liberiictis in a small village in the Gbi National Forest. A hunter had shot it that morning and it was being cooked on an open fire. Despite enquiring at numerous villages, the most I obtained was information about how the species was declining in many areas, that it was difficult to shoot, and that, if caught in a snare it was very fierce.

With the endorsement and encouragement of the IUCN/SSC Mustelid and Viverrid Specialist Group, we returned in 1989 to try to obtain several live animals to start a breeding programme at the Metro Toronto Zoo in Canada. On our second day in the field, in the town of Tapeta, my interpreter from the previous year brought us the skull and skin of a Liberian mongoose, which had been shot in the Gbi National Forest by a hunter in September 1988. We were much encouraged and decided to set up camp in the forest, well away from the nearest village, at the site of an 


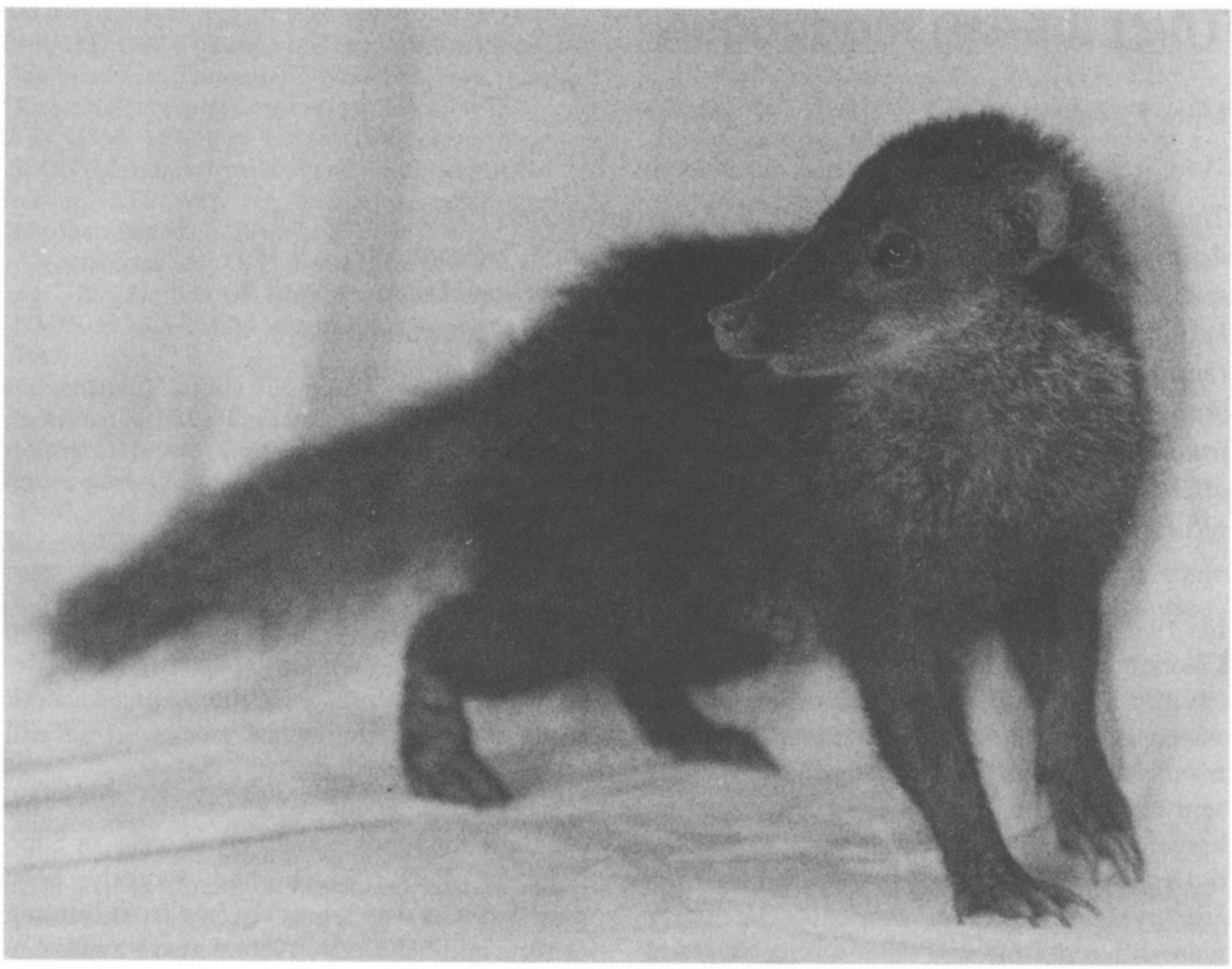

First black-and-white photograph of a Liberian mongoose (Mark Taylor).

old logging camp. The site appeared ideal, not only because it was connected to the road network in the forest, but also because it was close to disused roads no longer accessible to vehicles, which proved to be good game trails. We set out numerous live traps and an infrared-triggered camera. We used black-andwhite film so that we could develop it in the field. The first roll of film was exposed in a day, but on developing it we found that butterflies had been tripping the beam. After that we operated it at night and obtained pictures of civet, genet and a leopard, but none of the mongooses we were seeking.

I also spent time in villages outside the forest, talking to chiefs and hunters and distributing a brochure illustrating some of the animals in which we were interested. One day, while driving out of the forest, a young man rushed out waving a brochure. We stopped and he explained that he had caught one of the animals we were looking for. From the bottom of an old oil drum, a male Liberian mongoose peered up. The man had caught it in a snare and its back leg was injured, although the wound appeared largely superficial. We bought the animal, took it to camp and treated it with a course of antibiotics. We found it was partial to fresh fish and canned cat food, and within a week or so it was gaining weight, getting a good gloss to its coat, and its leg was healing well.

We visited the site where the mongoose was caught and found that it was deep in old secondary forest, very dark and overgrown with many vines hanging from the trees. The snare had been set on a game trail near the bank of a small dry creek; fresh worm casts were present in the stream bed. We learned from the villagers that this species also climbs into the heads of dead palm trees to dig out worms that thrive there. 
The Liberian mongoose was brought back to the Metro Toronto Zoo, and after a quarantine period was introduced to a special new exhibit. It has to search for some of its food among the litter and spends a lot of time climbing around in the branches provided. Because it is diurnal, visitors are often able to watch it as it scrambles about.

More recently, another biologist from Ontario, Mary Gartshore, was fortunate enough to come across a Liberian mongoose while working in the Tai National Forest in Côte d'Ivoire in 1990. She had seen our mongoose in the Metro Toronto Zoo and so was on the look-out. She described her sighting as follows: "The animal emerged from behind the palm and immediately began feeding. I saw the black mark on the neck immediately and felt greatly privileged that I should have such a splendid view of this rare mammal. I watched it for about 10 minutes (15.55-16.04) on 30 January 1990 . It was about $15-20$ feet away most of the time. During this time it searched for food constantly. It did this by burrowing into the damp black muck along

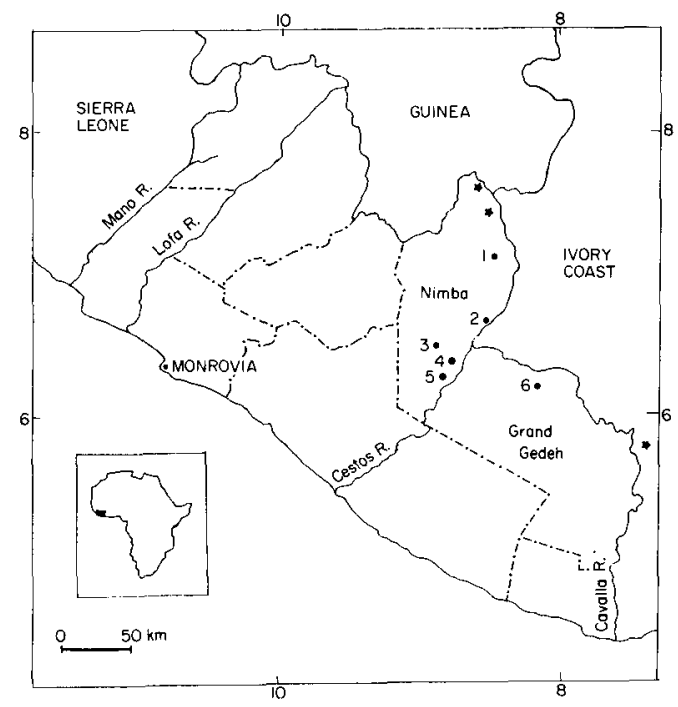

Figure 1. Localities where specimens of Liberiict is kuhni have been collected. 1. Gaple; 2 . Kpeaple; 3. Tapeta area; $4.32 \mathrm{~km}$ SE of Tapeta; 5 . near Nimnowehn; 6. 'Frog City' and Tar; * indicates localities where individuals have been sighted including new record from Tai National Park, Ivory Coast (After Goldman and Taylor, 1990).

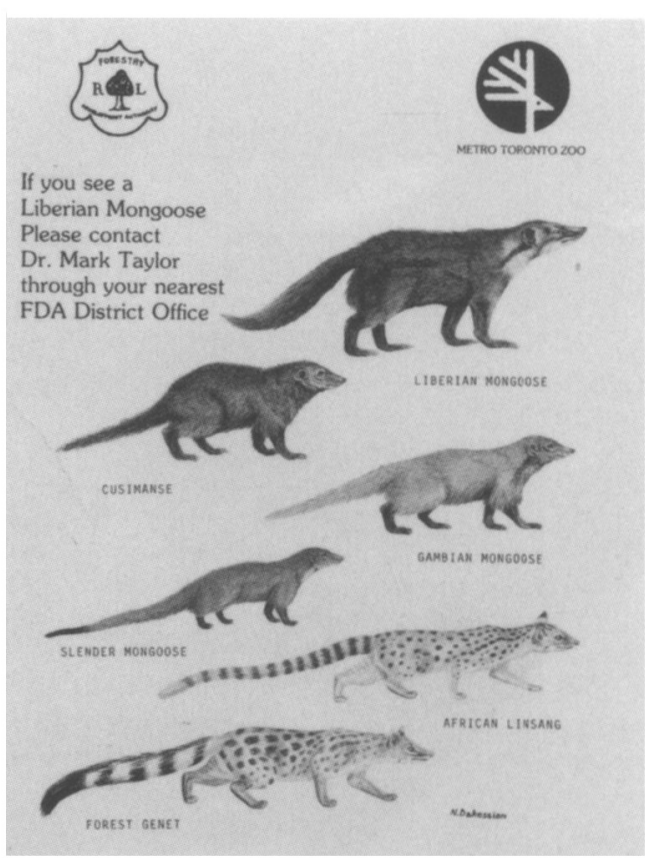

Colour brochure used by team to notify villagers of our interest in some of the viverrids in Liberia.

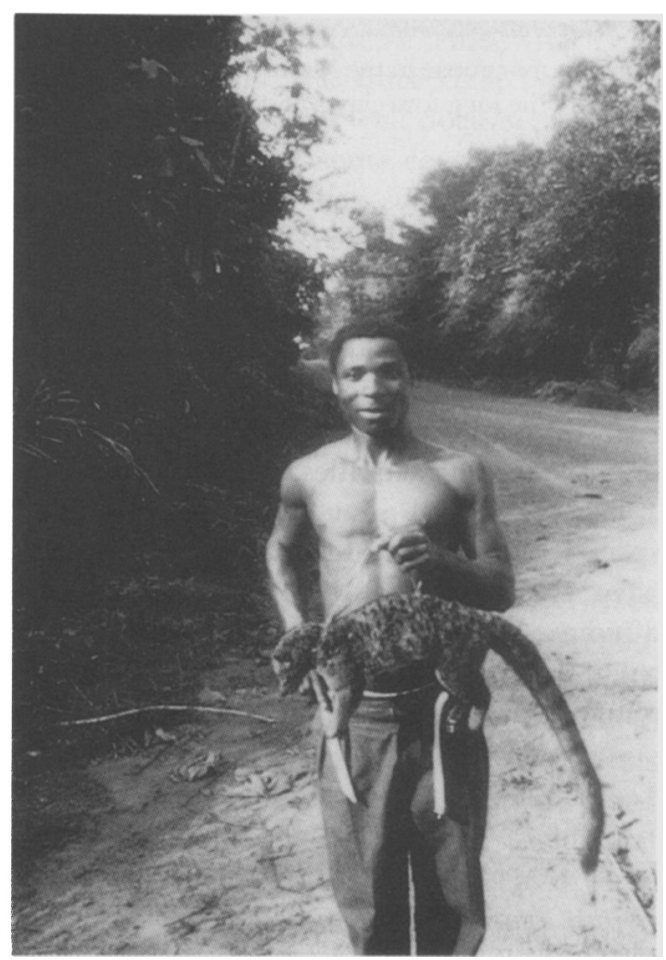

Hunter with palm civet for sale by roadside in north-eastern Liberia (Mark Taylor). 


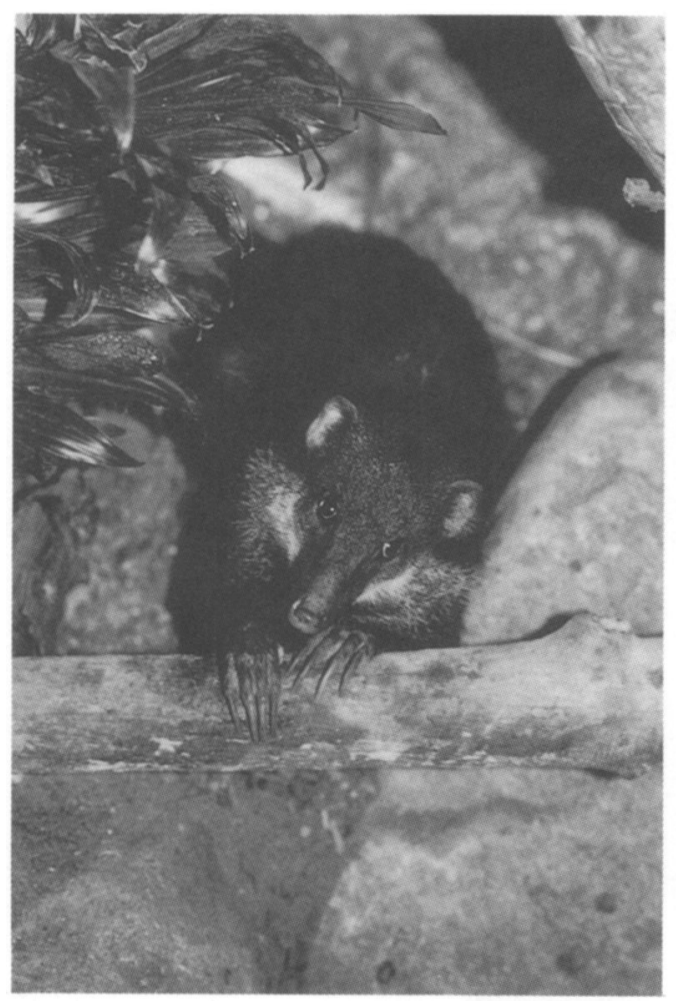

Liberian mongoose in the Metro Toronto Zoo showing the long fore claws and pointed snout (Mark Taylor).

the stream with its front feet, using them alternately like a dog and immediately shoving its nose down the hole. Occasionally it raised its head and looked around-probably listening. I then noticed that the whole stream bed had been turned over in the fashion that resulted from the feeding activities of this mammal.'

This is the first accurate description of the species from outside Liberia, although others have suggested that it occurs in the Côte d'Ivoire (Hoppe-Dominik, 1990). With the continued civil war in Liberia and a flood of refugees crossing to Côte d'Ivoire, it is impos- sible to continue field work for the time being. However, the Liberian mongoose in the Metro Toronto Zoo is safe and doing well and it is hoped that when the situation in West Africa improves, it will be possible to continue the work to investigate the ecological role that this rare viverrid plays in the forest ecosystem and to carry on with the breeding programme.

\section{Acknowledgments}

I would like to acknowledge the generous funding for this work from the Metropolitan Toronto Zoo and the Toronto Zoological Society, from the Fauna and Flora Preservation Society, the Royal Ontario Museum, the Zoological Society for the Conservation of Species and Populations, Munich, and the World Pheasant Association. Considerable support was also provided by EXCHEM, Liberia, the US Military Mission in Liberia, the Smithsonian Institution, the Liberian Forestry Development Authority, and Carsen Photographic, Canada.

\section{References}

Frame, G.W. and Schmude, C. 1986. Integrated Management and Development plan for Sapo National Park and Surrounding Areas in Liberia. Project 3216 WWF/IUCN, Gland, Switzerland, 66pp.

Goldman, C.A. and Taylor, M.E. 1990. Liberiict is kuhni: Mammalian Species No. 348, 1-3. American Society of Mammalogists.

Hayman, R.W. 1958. A new genus and species of West African mongoose. Annals and Magazine of Natural History, ser. 13, 1, 448-452.

Hoppe-Dominik, B. 1990. On the occurrence of the Honey Badger (Mellivora capensis) and the viverrids in the Ivory Coast. Mustelid and Viverrid Conservation, No. 3, 9-13.

Schlitter, D.A. 1974. Notes on the Liberian mongoose, Liberiictis kuhni Hayman 1958. Journal of Mammalogy, 55, 438-442.

Taylor, M.E. 1989. New records of two species of rare viverrids from Liberia. Mammalia, 53, 122-125.

Mark E. Taylor, Department of Zoology, University of Toronto, Toronto, Ontario M5S 1A1, Canada. 